\title{
Unique Usage of a Classical Selective Homodecoupling Sequence for High-Resolution Quantitative ${ }^{1} \mathrm{H}$ NMR
}

\author{
Naoki Saito*, , Takanori Komatsu§, Takako Suematsu§, Tetsuo Miyamoto§, Toshihide \\ Ihara ${ }^{\dagger}$ \\ † National Metrology Institute of Japan (NMIJ), National Institute of Advanced Industrial Science and \\ Technology (AIST), 1-1-1 Umezono, Tsukuba, Ibaraki 305-8563, Japan \\ § JEOL RESONANCE Inc., 3-1-2 Musashino, Akishima, Tokyo 196-8558, Japan
}

\section{Table of contents}

\section{Experimental Section}

Materials and apparatus

Comparison of DEP purity assays

(1) Conventional method

(2) Proposed method with presaturation

(3) Proposed method

DPrP purity assay using proposed method

\section{Results}

Figure SI1: High resolution ${ }^{1} \mathrm{H}$-qNMR spectrum of the DEP sample solution with proposed method.

Figure SI2: Comparison of changes in signal areas on ${ }^{1} \mathrm{H}$ NMR spectrum of the DEP sample solution.

Figure SI3: Changes in signal areas obtained by proposed method with the presaturation.

Figure S14: Correction of the signal area of impurity MPrP overlapping to DPrP.

Figure SI5: Indirect correction of the MPrP signal area in non-homodecoupled spectrum.

Table SI1: Calculated irradiation RF strengths.

Table SI2: Verification results of the DEP purity using non-homodecoupled ${ }^{1} \mathrm{H}$-qNMR.

Table SI3: Comparison results of DEP purity assays.

Table S14: Differences between frequency difference of the irradiation irr1 to the signal IS and that of the DEP signal $B$ to the irradiation irr2.

Table SI5: All purity values of DPrP corrected by the two different MPrP integration methods.

Table SI6: Uncertainty budget of the DPrP purity value obtained by proposed method.

Table SI7: Verification results of the DPrP purity using non-homodecoupled ${ }^{1} \mathrm{H}$-qNMR. 


\section{Experimental Section}

\section{Materials and apparatus}

Diethyl phthalate (DEP, NMIJ CRM 4022-b, National Metrology Institute of Japan, Ibaraki, Japan; purity $0.9998 \mathrm{~kg} \mathrm{~kg}^{-1} \pm 0.0001 \mathrm{~kg} \mathrm{~kg}^{-1}$ as the indicative value, the number after " \pm " indicates the expanded uncertainty of the coverage factor $k=2$ ) and dipropyl phthalate (DPrP, NMIJ 4025-a, National Metrology Institute of Japan; purity $0.9841 \mathrm{~kg} \mathrm{~kg}^{-1} \pm 0.0124 \mathrm{~kg} \mathrm{~kg}^{-1}$ as the certified value, $k=2$ ) were used as samples. The DPrP includes structurally similar impurity methyl propyl phthalate (MPrP). The internal standard for ${ }^{1} \mathrm{H}$-qNMR was 1,4-bis(trimethylsilyl)benzene- $d_{4}$ (1,4-BTMSB- $d_{4}$, FUJIFILM Wako Pure Chemical Co., Osaka, Japan; purity $0.999 \mathrm{~kg} \mathrm{~kg}^{-1} \pm 0.005$ $\mathrm{kg} \mathrm{kg}^{-1}, k=2$ ). Acetone- $d_{6}$ (FUJIFILM Wako Pure Chemical Co.; deuteration ratio 99.9\%) and pyridine- $d_{5}$ (FUJIFILM Wako Pure Chemical Co.; deuteration ratio 99.5\%) were used as solvents. A microbalance with $1 \mu \mathrm{g}$ resolution (XP56, Mettler-Toledo Inc., Greifensee, Switzerland) and an ultra-microbalance with $0.1 \mu \mathrm{g}$ resolution (XP6U, Mettler-Toledo Inc.) were used. A $500 \mathrm{MHz}{ }^{1} \mathrm{H}$ NMR spectrometer (ECZ500 while employing Delta version 5.2 software, JEOL Ltd., Tokyo, Japan) with a $5 \mathrm{~mm}$ probe (ROYAL, JEOL Ltd.) and MestreNova ver. 7.0.2 (Mestrelab Research, Santiago de Compostela, Spain) spectral software were used.

\section{Comparison of DEP purity assays}

A DEP sample solution was prepared by dissolving $10 \mathrm{mg} \mathrm{mL}^{-1}$ DEP and $1 \mathrm{mg} \mathrm{mL}^{-1}$ 1,4 -BTMSB- $d_{4}$ as the internal standard for ${ }^{1} \mathrm{H}$-qNMR in acetone- $d_{6}$. The solution was measured using (1) the conventional method, (2) the proposed method with presaturation and (3) the proposed method (see Figure 2).

\section{(1) Conventional method}

The DEP sample solution was measured using the pulse sequence "qnmr_experiment". Parameter settings were the following: spectrum width, 15 ppm (DSP with filter limit 4); frequency offset, $2.3 \mathrm{ppm}$; acquisition time, $4 \mathrm{~s}$; flip angle, $90^{\circ}$ (pulse width, $6.7 \mu \mathrm{s}$ ); sample temperature, $25{ }^{\circ} \mathrm{C}$; receiver gain, 46; dummy scans, 2; relaxation delay, $90 \mathrm{~s}$; number of scans, $32 ;{ }^{1} \mathrm{H}$ homodecoupling, on; decoupling offset, 1.30 ppm; decoupling attenuations, $96 \mathrm{~dB}$ to $42 \mathrm{~dB}$ (the attenuation was changed by $3 \mathrm{~dB}$ ). In the sequence, the presaturation was automatically added when the ${ }^{1} \mathrm{H}$ homodecoupling became active. The offset and attenuation of the presaturation were automatically set to the same as those of the ${ }^{1} \mathrm{H}$ homodecoupling. The solution was measured by three times at each decoupling attenuation.

On observed NMR spectra, the chemical shift was referenced to the acetone- $d_{5}$ signal at 2.05 ppm. To accurately quantify signal areas of the analyte signal B of the $\mathrm{O}-\mathrm{CH}_{2}$ group of DEP and the internal standard signal, the spectra were analyzed using manual phase corrections, 
integration range settings and baseline corrections. The integral ranges included ${ }^{13} \mathrm{C}$ satellites and cyclic irradiation sidebands. The baseline corrections were performed using the algorithm of linear segments. The analyte purities were calculated using Eq. (1).

$$
P_{\mathrm{a}}=\frac{S_{\mathrm{a}}}{S_{\mathrm{IS}}} \frac{H_{\mathrm{IS}}}{H_{\mathrm{a}}} \frac{W_{\mathrm{IS}}}{W_{\mathrm{AS}}} \frac{M_{\mathrm{a}}}{M_{\mathrm{IS}}} P_{\mathrm{IS}}
$$

Here, $P$ is purity as a mass fraction $\left(\mathrm{kg} \mathrm{kg}^{-1}\right), S$ is the ${ }^{1} \mathrm{H}$ signal area, $H$ is the number of ${ }^{1} \mathrm{H}$ nuclei on one molecule contributing to the ${ }^{1} \mathrm{H}$ signal area, $W$ is the weighing value $(\mathrm{mg}), M$ is molar mass $\left(\mathrm{g} \mathrm{mol}^{-1}\right)$, and subscripts AS, a, and IS refer to the sample, analyte, and internal standard respectively.

\section{(2) Proposed method with presaturation}

The DEP sample solution was measured using the pulse sequence "proton.jxp". Parameter settings were the following: spectrum width, 15 ppm (DSP with filter limit 4); frequency offset, 2.3 ppm; acquisition time, $3.5 \mathrm{~s}$; flip angle, $90^{\circ}$ (pulse width, $6.7 \mu \mathrm{s}$ ); sample temperature, $25{ }^{\circ} \mathrm{C}$; receiver gain, 46; dummy scans, 2; relaxation delay, $60 \mathrm{~s}$; number of scans, $32 ;{ }^{1} \mathrm{H}$ homodecoupling, on; decoupling offsets, $1.30 \mathrm{ppm}$ and $3.21 \mathrm{ppm}$; decoupling attenuations, $96 \mathrm{~dB}$ to $42 \mathrm{~dB}$. The same attenuation value was used in the two decoupling offsets. The attenuations were changed by $3 \mathrm{~dB}$ in the maximum range of $96 \mathrm{~dB}$ to $42 \mathrm{~dB}$. In the sequence, the presaturations were automatically added when the ${ }^{1} \mathrm{H}$ homodecouplings became active. The offsets and attenuations of the presaturations were automatically set to the same as those of the ${ }^{1} \mathrm{H}$ homodecouplings. The solution was measured by three times at each decoupling attenuation. Observed NMR spectra were analyzed in the same way as the conventional method.

\section{(3) Proposed method}

The DEP sample solution was measured using the pulse sequence "proton_mod.jxp". The sequence was improved in order not to set automatically the presaturation when the ${ }^{1} \mathrm{H}$ homodecoupling became active. Parameter settings were the following: spectrum width, $15 \mathrm{ppm}$ (DSP with filter limit 4); frequency offset, $2.3 \mathrm{ppm}$; acquisition time, $3.5 \mathrm{~s}$; flip angle, $90^{\circ}$ (pulse width, $6.7 \mu \mathrm{s}$ ); sample temperature, $25^{\circ} \mathrm{C}$; receiver gain, 46; dummy scans, 2; relaxation delay, 60 $\mathrm{s}$; number of scans, $32 ;{ }^{1} \mathrm{H}$ homodecoupling, on; decoupling offsets, $1.30 \mathrm{ppm}$ and $3.21 \mathrm{ppm}$; decoupling attenuations, $96 \mathrm{~dB}$ to $42 \mathrm{~dB}$. The same attenuation value was used in the two decoupling offsets. The attenuations were changed by $3 \mathrm{~dB}$ in the maximum range of $96 \mathrm{~dB}$ to 42 $\mathrm{dB}$. The solution was measured by three times at each decoupling attenuation. Observed NMR spectra were analyzed in the same way as the conventional method and the proposed method with presaturation. 


\section{DPrP purity assay using proposed method}

A DPrP sample solution was prepared by dissolving $10 \mathrm{mg} \mathrm{mL}^{-1}$ DEP and $1 \mathrm{mg} \mathrm{mL}^{-1}$ $1,4-\mathrm{BTMSB}-d_{4}$ as the internal standard for ${ }^{1} \mathrm{H}$-qNMR in pyridine- $d_{5}$. The solution was measured using the proposed method (see Figure 3).

The solution was measured using the improved pulse sequence "proton_mod.jxp". Parameter settings were the following: spectrum width, 15 ppm (DSP with filter limit 4); frequency offset, 2.2 ppm; acquisition time, $3.5 \mathrm{~s}$; flip angle, $90^{\circ}$ (pulse width, $6.7 \mu \mathrm{s}$ ); sample temperature, $25{ }^{\circ} \mathrm{C}$; receiver gain, 46; dummy scans, 2 ; relaxation delay, $60 \mathrm{~s}$; number of scans, $32 ;{ }^{1} \mathrm{H}$ homodecoupling, on; decoupling offsets, $1.61 \mathrm{ppm}$ and $2.85 \mathrm{ppm}$; decoupling attenuations, $51 \mathrm{~dB}$. The solution was measured by four times.

On observed NMR spectra, the chemical shift was referenced to the pyridine- $d_{4}$ signal on the lowest magnetic field side at $8.74 \mathrm{ppm}$. To accurately quantify signal areas of the analyte signal B' of the $\mathrm{O}-\mathrm{CH}_{2}$ group of DPrP and the internal standard signal, the spectra were analyzed using manual phase corrections, integration range settings and baseline corrections in the same way as the DEP purity assays. The signal $\mathrm{X}$ area of the $\mathrm{O}-\mathrm{CH}_{2}$ group of the structurally related impurity MPrP overlapping to the signal B' of DPrP was subtracted on the spectrum. Two different MPrP integration methods a) valley-to-valley and b) vertical drop line were adopted due to not being able to draw approximate baselines of Lorentzian or Gaussian using Mnova ver. 7.0.2 (Fig. SI4). In each spectrum, an arithmetic mean of two purity values of DPrP corrected by the two different MPrP integration methods was obtained. The arithmetic mean of the obtained four mean values was used as the final value (Table SI5). 

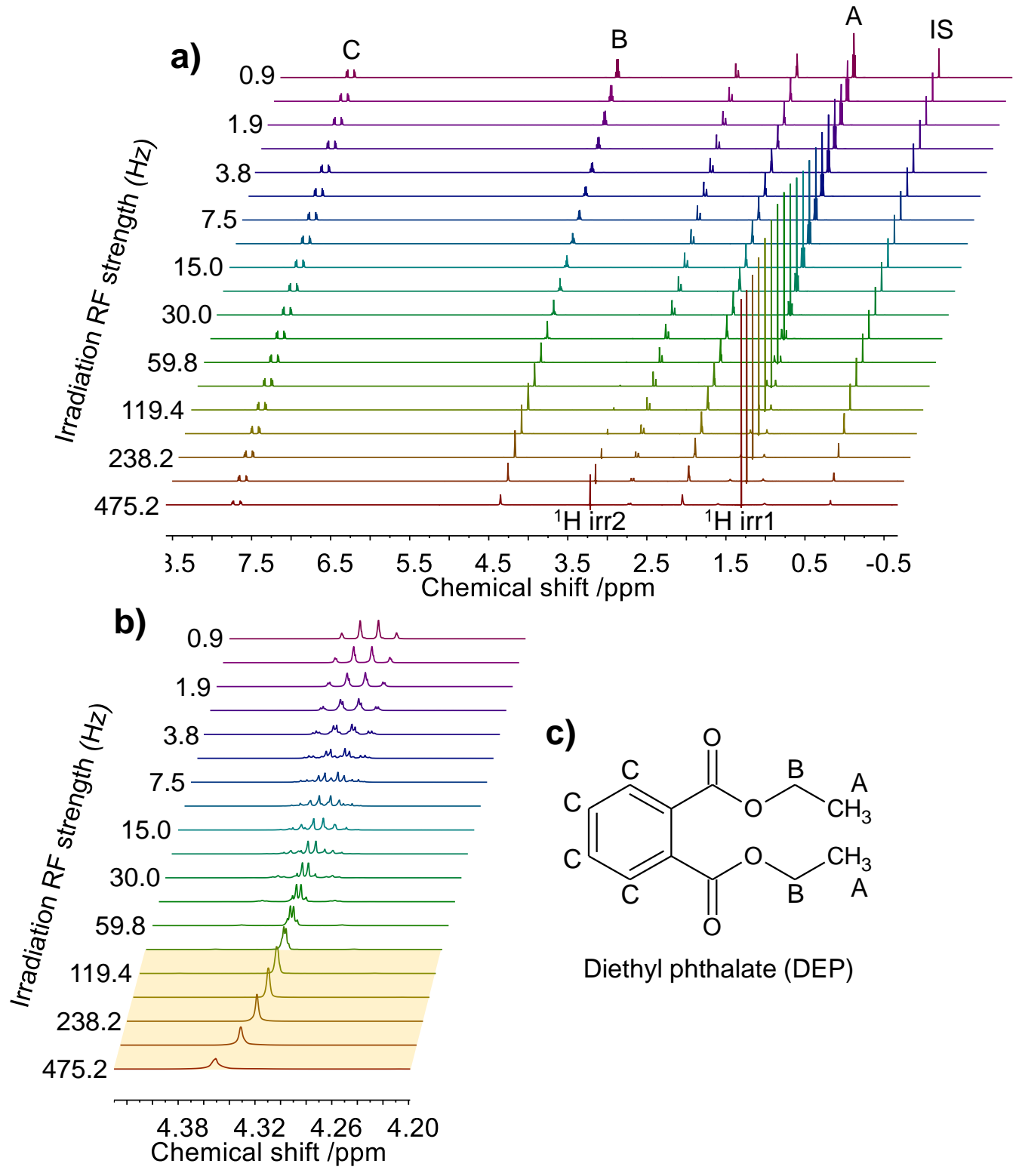<smiles>[B]COC(=O)c1ccccc1C(=O)OCC</smiles>

Diethyl phthalate (DEP)

Figure SI1. High resolution ${ }^{1} \mathrm{H}$-qNMR spectrum of the DEP sample solution with proposed method. a) Overviews of spectra obtained by using different irradiation RF strengths, b) expanded spectra in regions of the signal $\mathrm{B}$ of $\mathrm{O}-\mathrm{CH}_{2}$ group of DEP and c) structural formula of DEP. The yellow area is the effective decoupling area to become a singlet of the signal $\mathrm{B}$. The data are spectra which were used for DEP purity assays by the proposed method shown in Fig. 2. 

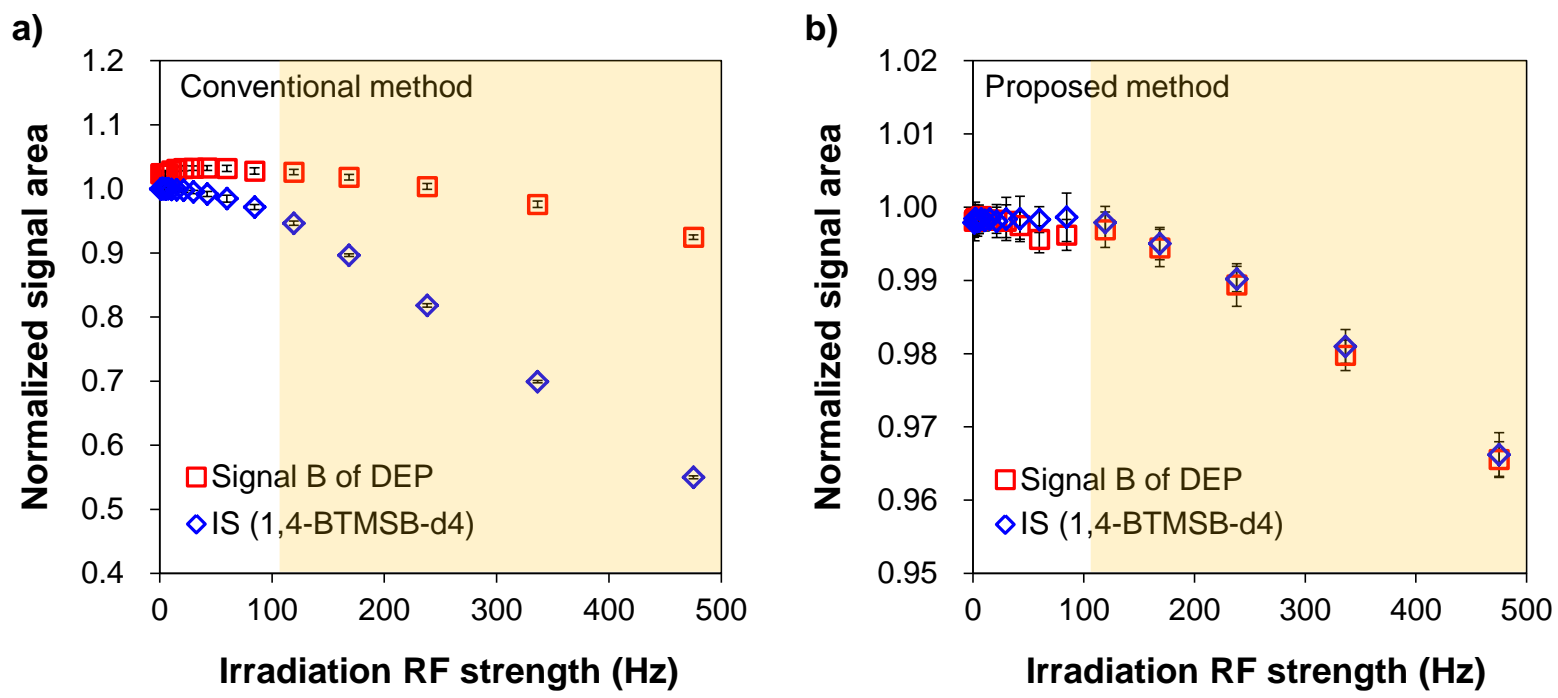

Figure S12. Comparison of changes in signal areas on ${ }^{1} \mathrm{H}$ NMR spectrum of the DEP sample solution. a) The case of using conventional method and b) that of using the proposed method. In either case a) or b), the signal areas were normalized by using the initial value when the irradiation RF strength was $0.9 \mathrm{~Hz}$. The yellow area is the effective decoupling area. An error bar is shown as a doubled standard deviation obtained by three repeated measures at the same attenuation. The data are signal areas which were used for DEP purity assays shown in Fig. 2. 


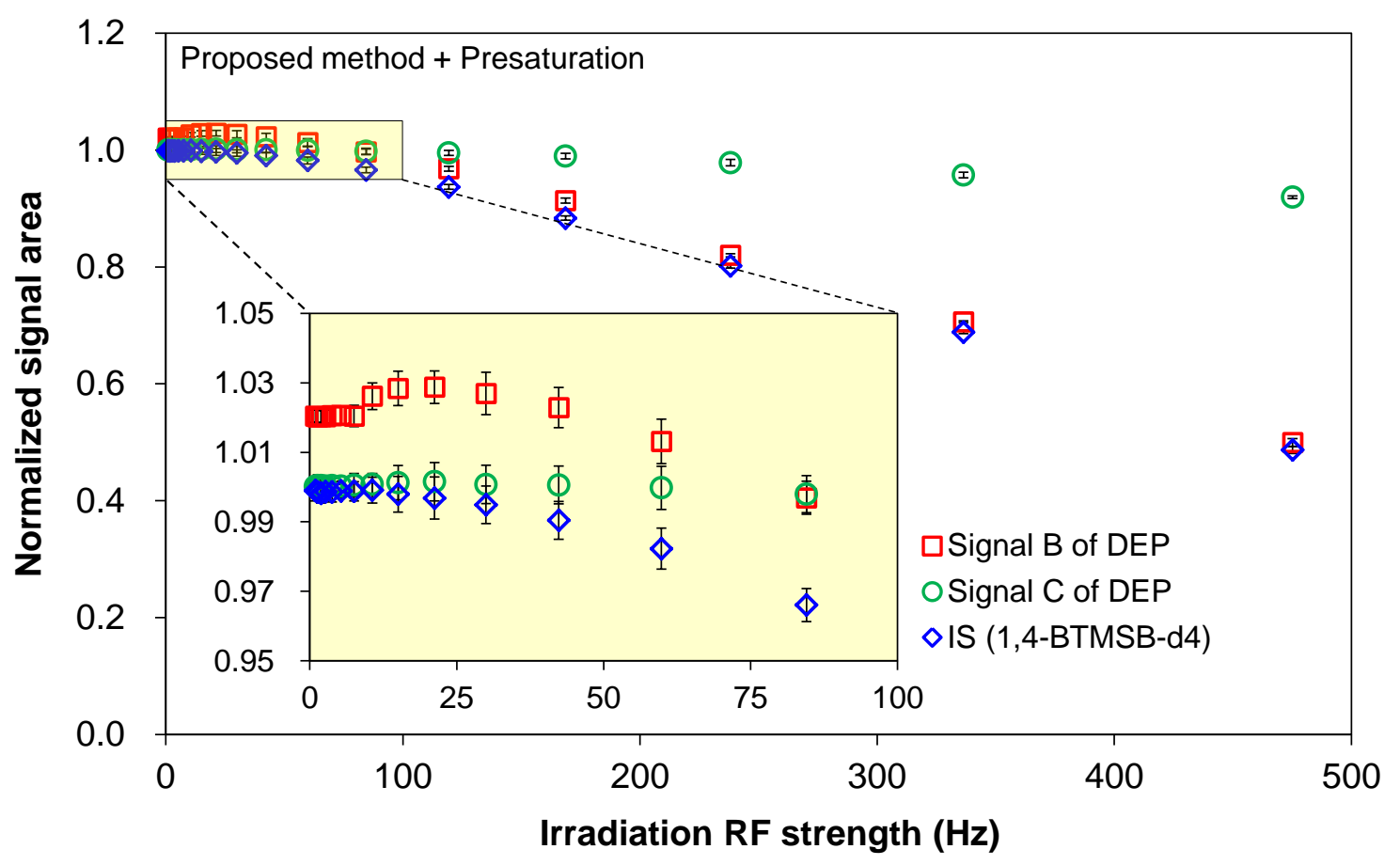

Figure SI3. Changes in signal areas obtained by proposed method with the presaturation. a) Full scale graph and b) expanded scale graph in the yellow area. The signal areas were normalized by using the initial value when the irradiation RF strength was $0.9 \mathrm{~Hz}$. An error bar is shown as a doubled standard deviation obtained by three repeated measures at the same attenuation. Except for the data of the signal $\mathrm{C}$ of aromatic ${ }^{1} \mathrm{H}$ nuclei of DEP, the data are signal areas which were used for DEP purity assays shown in Fig. 2. 
a)

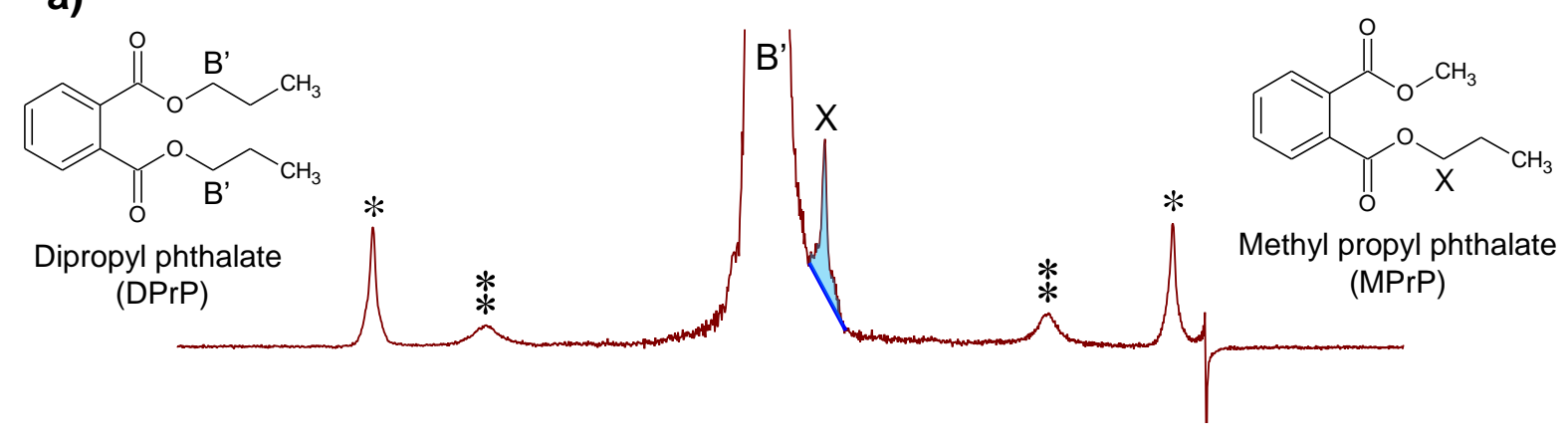

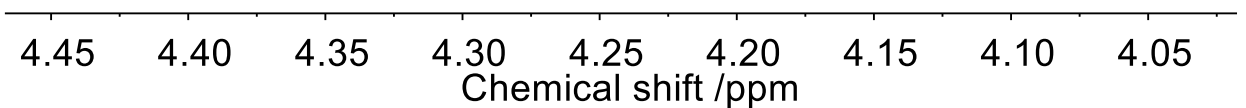

b)

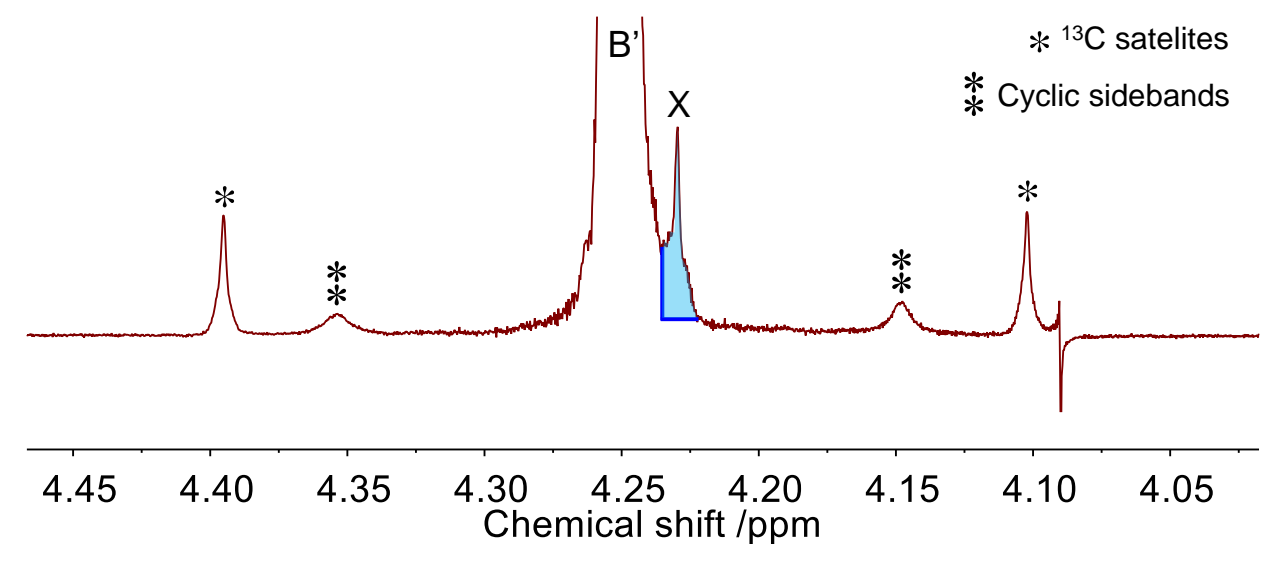

Figure S14. Correction of the signal area of impurity MPrP overlapping to DPrP. The integral area (shown in the blue area) of the signal $X$ of impurity MPrP overlapping on the foot of the DPrP signal B' was subtracted by two different integration methods a) valley-to-valley and b) vertical drop line in the same ${ }^{1} \mathrm{H}$ homodecoupled spectrum. The obtained DPrP purity values are shown in Table SI5. 


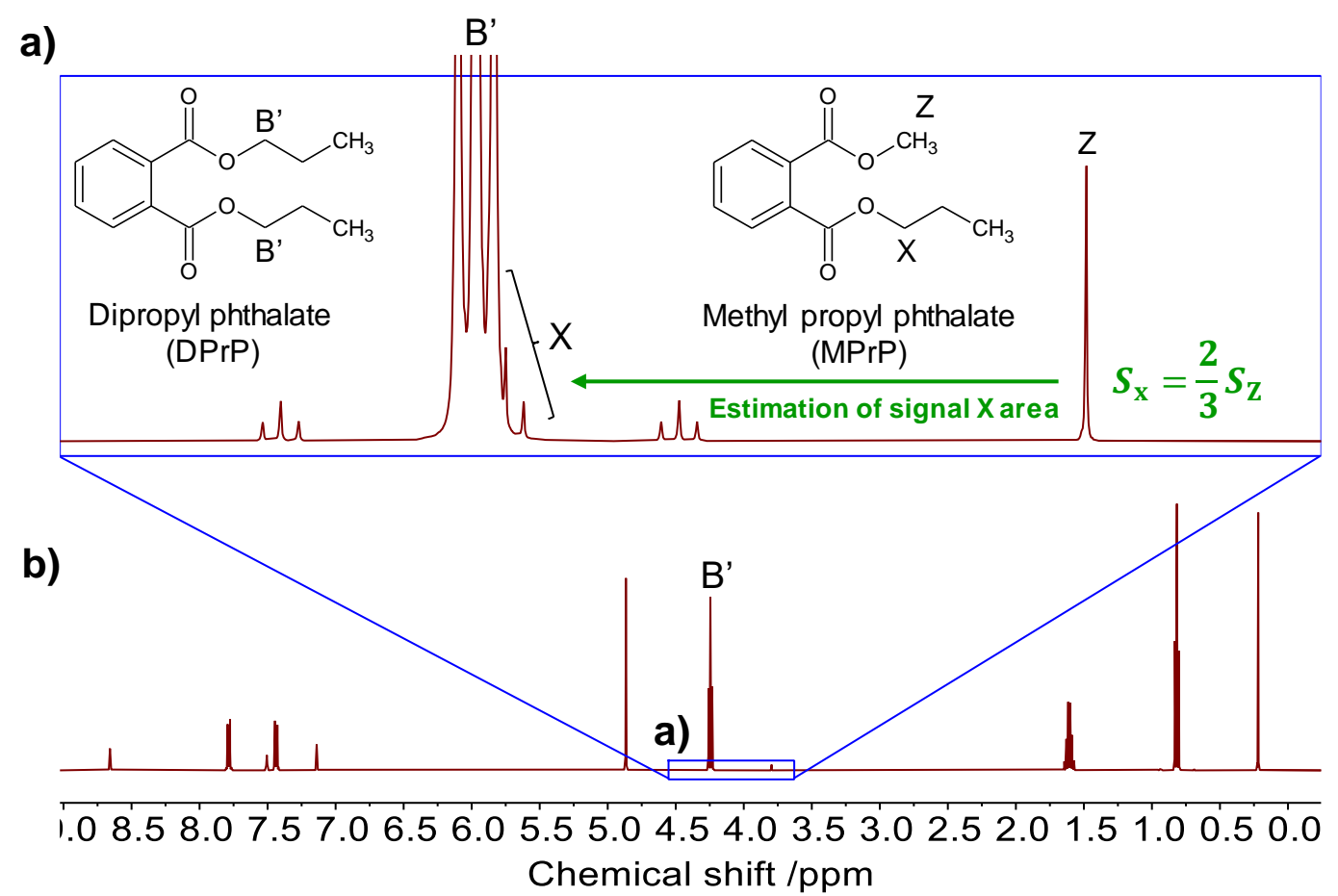

Figure SI5. Indirect correction of the MPrP signal area in non-homodecoupled spectrum. a) Non-homodecoupled expanded spectrum in the DPrP signal B' and the MPrP signal Z region, b) overview of the spectrum. The triplet signal $X$ area of impurity MPrP overlapping to the DPrP signal $B^{\prime}$ is two-thirds as large as the MPrP signal $Z$ area. The indirectly estimated signal $X$ area was subtracted from total signal areas of signals B' and X. The obtained DPrP purity values are shown in Table SI7. 
Table SI1. Calculated irradiation RF strengths.

\begin{tabular}{crrr}
\hline $\begin{array}{c}\text { Decoupling attenuation } \\
(\mathrm{dB})\end{array}$ & $\begin{array}{c}{ }^{1} \mathrm{H} \text { pulse } \text { width }^{[\mathrm{a}]} \\
(\mu \mathrm{s})\end{array}$ & $\begin{array}{c}\text { Irradiation RF strength } \\
\left(\gamma \mathrm{B}_{2} / 2 \pi, \mathrm{Hz}\right)\end{array}$ \\
\hline 96 & 263678.6 & 0.9 \\
93 & 186670.1 & 1.3 \\
& 90 & 132152.3 & 1.9 \\
87 & 93556.7 & 2.7 \\
84 & 66233.1 & 3.8 \\
81 & 46889.4 & 5.3 \\
78 & 33195.2 & 7.5 \\
75 & 23500.4 & 10.6 \\
72 & 16637.0 & 15.0 \\
69 & 11778.1 & 21.2 \\
66 & 8338.2 & 30.0 \\
63 & 5903.0 & 42.4 \\
60 & 4179.0 & 59.8 \\
57 & 2958.5 & 84.5 \\
54 & 2094.5 & 119.4 \\
51 & 1482.8 & 168.6 \\
48 & 1049.7 & 238.2 \\
45 & 743.1 & 336.4 \\
42 & 526.1 & 475.2 \\
\hline
\end{tabular}

[a] The value was converted from the decoupling attenuation in addition to the pulse width and the attenuation of the hard 90 degree pulse.

[b] The value was calculated using the converted ${ }^{1} \mathrm{H}$ pulse width. 
Table SI2. Verification results of the DEP purity using non-homodecoupled ${ }^{1} \mathrm{H}$-qNMR. The indicative value of DEP in the certificate is $99.98 \%$.

\begin{tabular}{lccccc}
\hline & $\begin{array}{c}\text { Run 1 } \\
(\%)\end{array}$ & $\begin{array}{c}\text { Run 2 } \\
(\%)\end{array}$ & $\begin{array}{c}\text { Run 3 } \\
(\%)\end{array}$ & $\begin{array}{c}\text { Run 4 } \\
(\%)\end{array}$ & $\begin{array}{c}\text { Mean } \\
(\%)\end{array}$ \\
\hline $\begin{array}{l}\text { DEP signal B }\left(\mathrm{O}-\mathrm{CH}_{2}\right) \text { on } \\
\text { non-decoupled spectrum }\end{array}$ & 99.94 & 99.91 & 99.93 & 100.00 & 99.95 \\
\hline
\end{tabular}

[a] Measurement parameter settings were the following: spectrum width, $15 \mathrm{ppm}$ (DSP with filter limit 4); frequency offset, $2.3 \mathrm{ppm}$; acquisition time, $4 \mathrm{~s}$; flip angle, $90^{\circ}$ (pulse width, $6.7 \mu \mathrm{s}$ ); sample temperature, $25^{\circ} \mathrm{C}$; receiver gain, auto; dummy scans, 2; relaxation delay, $90 \mathrm{~s}$; number of scans, 32. Observed NMR spectra were analyzed in the same way as the conventional method shown on pp.S2-S3. 
Table SI3. Comparison results of DEP purity assays. All the purity values in Fig. 2 are shown. The indicative value of DEP in the certificate is $99.98 \%$.

\begin{tabular}{rccc}
\hline $\begin{array}{c}\text { Irradiation } \\
\text { RF strengths } \\
\left(\gamma \mathrm{B}_{2} / 2 \pi, \mathrm{Hz}\right)\end{array}$ & $\begin{array}{c}\text { Conventional method }{ }^{[a]} \\
(\%)\end{array}$ & $\begin{array}{c}\text { Proposed method } \\
\text { +Presaturation }\end{array}$ & $\begin{array}{c}\text { Pr] } \\
(\%)\end{array}$ \\
\hline 0.9 & $102.35 \pm 0.06$ & $102.09 \pm 0.13$ & $1 \%)$ \\
1.3 & $102.34 \pm 0.12$ & $102.11 \pm 0.01$ & $100.02 \pm 0.07$ \\
1.9 & $102.30 \pm 0.06$ & $102.16 \pm 0.12$ & $99.98 \pm 0.16$ \\
2.7 & $102.29 \pm 0.17$ & $102.11 \pm 0.06$ & $99.99 \pm 0.01$ \\
3.8 & $102.30 \pm 0.14$ & $102.15 \pm 0.07$ & $100.01 \pm 0.12$ \\
5.3 & $102.31 \pm 0.11$ & $102.13 \pm 0.06$ & $100.01 \pm 0.07$ \\
7.5 & $102.30 \pm 0.06$ & $102.12 \pm 0.06$ & $100.02 \pm 0.15$ \\
10.6 & $102.88 \pm 0.09$ & $102.65 \pm 0.02$ & $99.99 \pm 0.14$ \\
15.0 & $103.16 \pm 0.12$ & $103.00 \pm 0.04$ & $99.97 \pm 0.03$ \\
21.2 & $103.39 \pm 0.12$ & $103.15 \pm 0.16$ & $100.00 \pm 0.14$ \\
30.0 & $103.68 \pm 0.12$ & $103.16 \pm 0.08$ & $99.95 \pm 0.08$ \\
42.4 & $104.05 \pm 0.12$ & $103.23 \pm 0.04$ & $99.89 \pm 0.12$ \\
59.8 & $104.73 \pm 0.11$ & $103.09 \pm 0.12$ & $99.71 \pm 0.08$ \\
84.5 & $105.74 \pm 0.18$ & $103.14 \pm 0.21$ & $99.74 \pm 0.12$ \\
119.4 & $108.39 \pm 0.12$ & $103.28 \pm 0.10$ & $99.88 \pm 0.03$ \\
168.6 & $113.51 \pm 0.29$ & $103.31 \pm 0.10$ & $99.93 \pm 0.09$ \\
238.2 & $122.65 \pm 0.19$ & $102.22 \pm 0.18$ & $99.90 \pm 0.13$ \\
336.4 & $139.55 \pm 0.37$ & $102.50 \pm 0.15$ & $99.86 \pm 0.03$ \\
475.2 & $168.04 \pm 0.17$ & $102.64 \pm 0.09$ & $99.91 \pm 0.09$ \\
\hline
\end{tabular}

[a] The number after " \pm " indicates the doubled standard deviation. A standard deviation was obtained by three repeated measures at the same attenuation. 
Table SI4. Differences between frequency difference of the irradiation irr1 to the signal IS and that of the DEP signal B to the irradiation irr2.

\begin{tabular}{rrrr}
\hline $\begin{array}{c}\text { Irradiation } \\
\mathrm{RF} \text { strengths } \\
\left(\gamma \mathrm{B}_{2} / 2 \pi, \mathrm{Hz}\right)\end{array}$ & $\begin{array}{c}\text { Frequency difference of } \\
\text { the irr1 to the signal IS } \\
(\mathrm{X}, \mathrm{Hz})\end{array}$ & $\begin{array}{c}\text { Frequency difference of } \\
\text { the DEP signal B to the irr2 } \\
(\mathrm{Y}, \mathrm{Hz})\end{array}$ & $\begin{array}{c}\mathrm{Y}-\mathrm{X} \\
(\mathrm{Hz})\end{array}$ \\
\hline 0.9 & 537.5 & 541.2 & 3.7 \\
1.3 & 537.4 & 541.3 & 3.9 \\
1.9 & 537.3 & 541.2 & 3.9 \\
2.7 & 537.4 & 541.3 & 3.9 \\
3.8 & 537.4 & 541.2 & 3.8 \\
5.3 & 537.3 & 541.1 & 3.8 \\
7.5 & 537.4 & 540.9 & 3.5 \\
10.6 & 537.4 & 541.2 & 3.8 \\
15.0 & 537.4 & 541.2 & 3.8 \\
21.2 & 537.4 & 541.3 & 3.9 \\
30.0 & 537.4 & 541.2 & 3.8 \\
42.4 & 537.6 & 541.3 & 3.7 \\
59.8 & 537.9 & 541.4 & 3.5 \\
84.5 & 538.2 & 541.7 & 3.5 \\
119.4 & 539.2 & 542.9 & 3.7 \\
168.6 & 540.9 & 544.2 & 3.3 \\
238.2 & 544.5 & 547.8 & 3.3 \\
336.4 & 551.2 & 554.5 & 3.3 \\
475.2 & 564.6 & 567.5 & 2.9 \\
\hline & & &
\end{tabular}


Table SI5. All purity values of DPrP corrected by the two different MPrP integration methods. In each spectrum, an arithmetic mean of two purity values corrected by the two methods was obtained. The arithmetic mean of the obtained four mean values was used as the final value (shown in Table 1).

\begin{tabular}{lccccc}
\hline & $\begin{array}{c}\text { Run 1 } \\
(\%)\end{array}$ & $\begin{array}{c}\text { Run 2 } \\
(\%)\end{array}$ & $\begin{array}{c}\text { Run 3 } \\
(\%)\end{array}$ & $\begin{array}{c}\text { Run 4 } \\
(\%)\end{array}$ & $\begin{array}{c}\text { Mean } \\
(\%)\end{array}$ \\
\hline Method a) valley-to-valley & 98.55 & 98.64 & 98.66 & 98.65 & $(98.62)$ \\
Method b) vertical drop line & 98.10 & 98.13 & 98.21 & 98.21 & $(98.16)$ \\
\hline Mean of methods a) and b) & 98.33 & 98.38 & 98.44 & 98.43 & 98.39 \\
\hline
\end{tabular}


Table SI6. Uncertainty budget of the DPrP purity value obtained by proposed method.

\begin{tabular}{|c|c|c|c|c|}
\hline Uncertainty component[a] & Symbol & $\begin{array}{l}\text { Value } \\
\qquad x_{i}\end{array}$ & $\begin{array}{c}\text { Standard } \\
\text { uncertainty } \\
u\left(x_{i}\right)\end{array}$ & $\begin{array}{c}\left|c u\left(x_{i}\right)\right| ; c=\partial P_{a} / \partial x_{i} \\
\left(\mathrm{~kg} \mathrm{~kg}^{-1}\right)\end{array}$ \\
\hline Repeatability of NMR & $\varepsilon_{\text {rep }}$ & $0 \mathrm{~kg} \mathrm{~kg}^{-1}$ & $0.00025 \mathrm{~kg} \mathrm{~kg}^{-1}$ & 0.00025 \\
\hline Integration of impurity MPrP & $\varepsilon$ int & $0 \mathrm{~kg} \mathrm{~kg}^{-1}$ & $0.00133 \mathrm{~kg} \mathrm{~kg}^{-1}$ & 0.00133 \\
\hline Total weight of tare and DPrP sample & $W_{\mathrm{t} 1+\mathrm{AS}}$ & $42.095 \mathrm{mg}$ & $0.0015 \mathrm{mg}$ & 0.00013 \\
\hline Weight of tare for DPrP sample & $W_{t 1}$ & $30.796 \mathrm{mg}$ & $0.0015 \mathrm{mg}$ & 0.00013 \\
\hline Total weight of tare and IS & $W_{\mathrm{t} 2+\mathrm{IS}}$ & $27.1366 \mathrm{mg}$ & $0.00049 \mathrm{mg}$ & 0.00035 \\
\hline Weight of tare for IS & $W_{\mathrm{t} 2}$ & $25.7545 \mathrm{mg}$ & $0.00049 \mathrm{mg}$ & 0.00035 \\
\hline Signal area of DPrP & $S_{a}$ & 6.4270 & Included in $\varepsilon_{\text {rep }}$ & - \\
\hline Signal area of IS & SIS & 3.9764 & Included in Erep & - \\
\hline Relaxation effect of DPrP signal & $R_{a}$ & 1 & 0.00003 & 0.00003 \\
\hline Relaxation effect of IS signal & $R_{I S}$ & 1 & 0.00003 & 0.00003 \\
\hline${ }^{1} \mathrm{H}$ natural abundance of DPrP & $H_{a}$ & 4 & 0.00036 & 0.00009 \\
\hline${ }^{1} \mathrm{H}$ natural abundance of IS & $H_{I S}$ & 18 & 0.00162 & 0.00009 \\
\hline Molar mass of DPrP & $M a$ & $250.294 \mathrm{~g} \mathrm{~mol}^{-1}$ & $0.014 \mathrm{~g} \mathrm{~mol}^{-1}$ & 0.00006 \\
\hline Molar mass of IS & Mis & $226.502 \mathrm{~g} \mathrm{~mol}^{-1}$ & $0.013 \mathrm{~g} \mathrm{~mol}^{-1}$ & 0.00006 \\
\hline Purity of internal standard (IS) & $P_{\text {IS }}$ & $0.999 \mathrm{~kg} \mathrm{~kg}^{-1}$ & $0.0025 \mathrm{~kg} \mathrm{~kg}^{-1}$ & 0.00246 \\
\hline Purity of DPrP & $P_{a}$ & $0.9839 \mathrm{~kg} \mathrm{~kg}^{-1}$ & & \\
\hline Combined standard uncertainty & $u_{\mathrm{c}}$ & & & $0.0029 \mathrm{~kg} \mathrm{~kg}^{-1}$ \\
\hline Expanded uncertainty $(k=2)$ & $U$ & & & $0.0058 \mathrm{~kg} \mathrm{~kg}^{-1}$ \\
\hline
\end{tabular}

[a] Eq. (1) shown on p.S3 was transformed to the following Eq (2):

$$
P_{\mathrm{a}}=\frac{R_{\mathrm{a}}}{R_{\mathrm{IS}}} \frac{S_{\mathrm{a}}}{S_{\mathrm{IS}}} \frac{H_{\mathrm{IS}}}{H_{\mathrm{a}}} \frac{W_{\mathrm{t} 2+\mathrm{IS}}-W_{\mathrm{t} 2}}{W_{\mathrm{t} 1+\mathrm{AS}}-W_{\mathrm{t} 1}} \frac{M_{\mathrm{a}}}{M_{\mathrm{IS}}} P_{\mathrm{IS}}+\varepsilon_{\mathrm{rep}}+\varepsilon_{\mathrm{int}}(2) \text {. }
$$

Here, subscripts a and IS refer to DPrP and 1,4-BTMSB- $d_{4}$, respectively. The uncertainty of integration of impurity MPrP was calculated by assuming a rectangular distribution having the half-width between the upper and lower limits, DPrP purity values $0.9862 \mathrm{~kg} \mathrm{~kg}^{-1}$ and $0.9816 \mathrm{~kg}$ $\mathrm{kg}^{-1}$ corrected by the two integration methods (shown in Fig. SI4 and Table SI5). 
Table SI7. Verification results of the DPrP purity using non-homodecoupled ${ }^{1} \mathrm{H}$-qNMR. The certified value of DPrP in the certificate is $98.41 \%$. This Table compares the DPrP purity values obtained by not correcting or indirectly correcting the signal $\mathrm{X}$ area of impurity MPrP overlapping to DPrP by the approach shown in Fig. SI5.

\begin{tabular}{lccccc}
\hline $\begin{array}{c}\text { DPrP signal B' }\left(\mathrm{O}-\mathrm{CH}_{2}\right) \text { on } \\
\text { non-decoupled spectrum }\end{array}$ & $\begin{array}{c}\text { Run } 1 \\
(\%)\end{array}$ & $\begin{array}{c}\text { Run 2 } \\
(\%)\end{array}$ & $\begin{array}{c}\text { Run 3 } \\
(\%)\end{array}$ & $\begin{array}{c}\text { Run 4 } \\
(\%)\end{array}$ & $\begin{array}{c}\text { Mean } \\
(\%)\end{array}$ \\
\hline Not correction of signal X area & 99.20 & 99.07 & 99.15 & 99.11 & 99.13 \\
Indirect correction of signal X area & 98.33 & 98.20 & 98.31 & 98.26 & 98.28 \\
\hline
\end{tabular}

[a] Measurement parameter settings were the following: spectrum width, $15 \mathrm{ppm}$ (DSP with filter limit 4); frequency offset, $2.2 \mathrm{ppm}$; acquisition time, $4 \mathrm{~s}$; flip angle, 90 (pulse width, $6.7 \mu \mathrm{s}$ ); sample temperature, $25^{\circ} \mathrm{C}$; receiver gain, auto; dummy scans, 2; relaxation delay, $60 \mathrm{~s}$; number of scans, 32. Observed NMR spectra were analyzed in the same way as the proposed method shown on p.S4. 